\title{
Oxygen limitation can trigger the production of branched GDGTs in culture
}

\author{
T.A. Halamka ${ }^{1 *}$, J.M. McFarlin ${ }^{1}$, A.D. Younkin ${ }^{1}$, J. Depoy ${ }^{1}$, N. Dildar ${ }^{1}$, S.H. Kopf ${ }^{1}$
}

Abstract

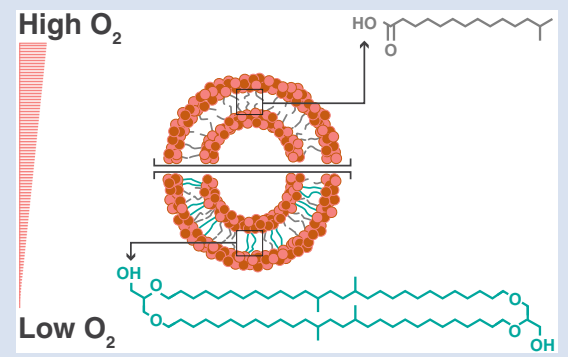

Branched glycerol dialkyl glycerol tetraethers (brGDGTs) are ubiquitous and well-preserved sedimentary biomarkers. These compounds serve as important palaeoenvironmental indicators due to strong empirical correlations between brGDGT distributions and temperature and $\mathrm{pH}$ in modern environments. However, the mechanistic link between temperature, $\mathrm{pH}$, and brGDGT production has been difficult to study due to uncertainty about the organisms and physiological conditions required for the synthesis of brGDGTs in nature. Here, we report that in the Acidobacterium Edaphobacter aggregans, severe oxygen limitation $\left(1 \% \mathrm{O}_{2}\right)$ leads to significant brGDGT production (2.9\% of membrane lipids) with three structural varieties including an uncharacterized isomer of brGDGT Ic. Low $\mathrm{O}_{2}$ as a physiological trigger for brGDGT production may help explain why brGDGT producers have been so difficult to identify, and provides a new path towards uncovering the genetic basis and biological function of brGDGTs. If the oxygen effects observed here apply more broadly, the empirical calibrations for brGDGT-based temperature and $\mathrm{pH}$ reconstructions may currently be missing the effects of oxygen as a relevant and possibly dominant control in the environmental distributions of brGDGTs.

\section{Introduction}

Methodological advances in sample preparation and analysis over the past decade have highlighted the vast global distribution of brGDGTs across terrestrial, aquatic, hydrothermal, and sedimentary systems (Lincoln et al., 2013; De Jonge et al., 2014; Weber et al., 2018; Wang et al., 2019). The relative abundances of structurally unique brGDGTs have been explored in many of these settings in efforts to calibrate brGDGTs as a palaeoenvironmental proxy by establishing empirical correlations with temperature and $\mathrm{pH}$, such as the Methylation index of Branched Tetraethers (MBT) and the Cyclization index of Branched Tetraethers (CBT), respectively (Weijers et al., 2007; Peterse et al., 2012; Naafs et al., 2017). Prior work has demonstrated that many Acidobacteria, a diverse and widespread phylum of soil bacteria, synthesise the potential brGDGT precursor iso-diabolic acid (13,16-dimethyl octacosanedioic acid) in large quantities (Sinninghe Damsté et al., 2018), and that some members of subdivision 1 (SD 1) Acidobacteria, including Edaphobacter aggregans, produce trace amounts of at least one brGDGT (Sinninghe Damsté et al., 2011). However, the lack of cultured organisms that consistently produce branched tetraethers raises the question of how these compounds are so structurally diverse and abundant in nature yet so elusive in the laboratory.

Here we investigated the effects of molecular oxygen availability $\left(\mathrm{O}_{2}\right)$ on brGDGT production to test the hypothesis that brGDGT production may require a specific environmental constraint. Many Acidobacteria including E. aggregans harbour high affinity terminal oxidases in their genomes (Eichorst et al., 2018). These types of oxidases often have half-saturation constants at low $\mathrm{nM}$ concentrations of $\mathrm{O}_{2}$, likely enabling survival and growth in micro-aerobic habitats (Pitcher and Watmough, 2004). Such low $\mathrm{O}_{2}$ availability is common in many soil, peat, and sedimentary environments and prior work on brGDGT distribution and production across oxygen gradients suggests that some environmental source organisms may preferentially grow at oxic/anoxic transitions (Liu et al., 2014; Weber et al., 2018; Martínez-Sosa and Tierney, 2019). To study the effects of $\mathrm{O}_{2}$ limitation, we examined the tetraether and fatty acid membrane composition of $E$. aggregans grown in a simplified yeast extract medium under $\mathrm{O}_{2}$ conditions ranging from fully aerated $\left(21 \% \mathrm{O}_{2}\right)$ to severely $\mathrm{O}_{2}$ limited $\left(1 \% \mathrm{O}_{2}\right)$. An excess additional carbon source (sucrose) was either added or omitted to control for the potential effects of growth rate.

\section{Results and Discussion}

The effects of $\mathrm{O}_{2}$ limitation. E. aggregans produced similar fatty acids under all growth conditions with the sum of just four fatty acids (iso-diabolic acid, iso-C15:0, C16:0, and C16:1) constituting over $90 \%$ of the fatty acid fraction (Fig. 1, Table S-1), consistent with previous observations in a different growth medium (91 \%; Sinninghe Damsté et al., 2011). Although the relative abundance of individual fatty acids differed significantly between culture conditions, the hypothesised brGDGT precursor

1. Department of Geological Sciences, University of Colorado, Boulder, Colorado 80309, USA

Corresponding author (email: toby.halamka@colorado.edu) 


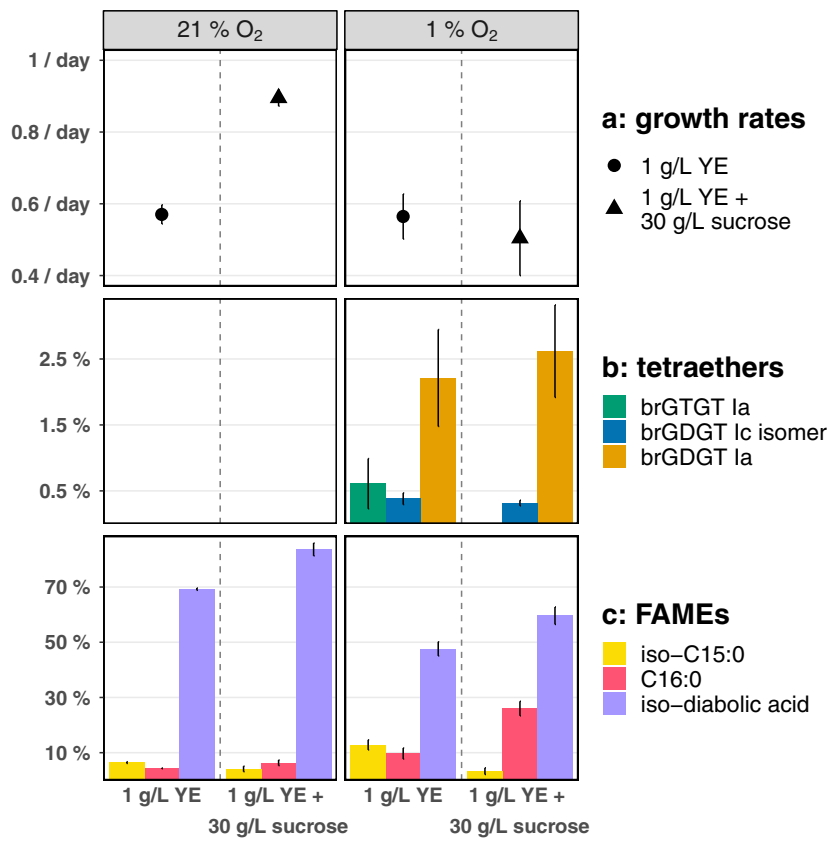

Figure 1 Growth rate and lipid membrane profiles of $E$. aggre gans grown in liquid culture at $21 \% \mathrm{O}_{2}$ (= air, left) and $1 \% \mathrm{O}_{2}$ (right) with and without carbon excess. Data points represent averages and standard deviations of biological triplicates. (a) Growth rates with medium containing $1 \mathrm{~g} / \mathrm{L}$ Yeast Extract (YE, circle) and $1 \mathrm{~g} / \mathrm{L} \mathrm{YE}+30 \mathrm{~g} / \mathrm{L}$ sucrose (triangle). (b) Tetraethers [\% of all detected core lipids]: brGTGT la (green), brGDGT Ic isomer (blue), brGDGT la (orange). No tetraethers were detected at $21 \% \mathrm{O}_{2}$ (c) Most abundant FAMEs (Fatty Acid Methyl Esters, \% of all detected core lipids): iso-C15:0 (light yellow), C16:0 (red), isodiabolic acid (purple).

iso-diabolic acid was always the dominant membrane core lipid ranging in relative abundance from $40 \pm 3 \%$ to $84 \pm 2 \%$ with a systematic decrease both at lower $\mathrm{O}_{2}$ and without sucrose. In liquid culture, the organism produced no detectable tetraethers at $21 \%$ and $5 \% \mathrm{O}_{2}$, however, at $1 \% \mathrm{O}_{2}$ E. aggregans produced significant quantities (up to $2.9 \pm 0.7 \%$ ) of up to three different tetraethers (brGDGT Ia, brGTGT Ia, and an uncharacterised isomer of brGDGT Ic; see Fig. 2 for structures).

Growth rates slowed significantly at lower $\mathrm{O}_{2}$ when grown with excess sucrose (from $0.89 \pm 0.02$ /day at $21 \% \mathrm{O}_{2}$ to $0.50 \pm 0.10 /$ day at $1 \% \mathrm{O}_{2}$ ) and remained unchanged when grown without sucrose $\left(0.57 \pm 0.03\right.$ /day at $21 \% \mathrm{O}_{2}$ to $0.56 \pm 0.06 /$ day at $1 \% \mathrm{O}_{2}$ ) but tetraether production in liquid culture was limited to $1 \% \mathrm{O}_{2}$ conditions independent of growth rate (Fig. 1, Table S-2). Temperature and $\mathrm{pH}$ were identical for all culturing conditions, suggesting that $\mathrm{O}_{2}$ limitation is the primary environmental trigger for brGDGT production in E. aggregans, with a threshold for biosynthesis in liquid culture between $5 \%$ and $1 \% \mathrm{O}_{2}$. However, E. aggregans, named for its tendency to aggregate, displays significant cellular clumping in liquid culture. Cell aggregates form natural $\mathrm{O}_{2}$ gradients (Wessel et al., 2014) and may trigger brGDGT biosynthesis by reducing $\mathrm{O}_{2}$ availability to individual cells deeper within the aggregates. Consequently, the actual biochemical $\mathrm{O}_{2}$ threshold for brGDGT production may be significantly lower.

Although the physiological role of brGDGTs is not yet understood, we speculate that brGDGT production in E. aggregans could be part of an energy stress response imposed by the lack of sufficient $\mathrm{O}_{2}$ for energy production. Such terminal electron acceptor limitation could place increased importance on the role of lipids in restricting membrane permeability. In Archaea, which produce isoprenoidal GDGTs (isoGDGTs), tetraether lipids are often inferred to play a similar role in combatting energy stress by decreasing the cellular membrane's proton permeability and thus decreasing maintenance energy costs (Qin et al., 2015). Recent work also suggests that the synthesis of ether bonds under oxygen limiting conditions is an energetic adaptation to reducing environments (Boyer et al., 2020). The structural attributes of the tetraether lipids that E. aggregans produces that may play a role in decreased membrane permeability include their membrane spanning nature and ether bonds. Specifically, membrane spanning lipids increase membrane rigidity and stability and ether-bound lipids have been found to decrease membrane permeability relative to esterbound lipids (Van de Vossenberg et al., 1998).

Tetraether structures. The tetraethers of E. aggregans were identified based on their retention times and fragmentation patterns as brGDGT Ia, brGTGT Ia (Glycerol Trialkyl Glycerol Tetraether), and a structural isomer of brGDGT Ic (Fig. 2). Retention time offsets between the newly described tetraethers (brGDGT Ic isomer and brGTGT Ia) and previously described structurally similar tetraethers (brGDGT Ic and C46 GTGT) are shown in Figure $2 b$. These data confirm and quantify for the first time the previously suspected production of brGDGT Ia in E. aggregans (Sinninghe Damsté et al., 2011), and reveal the capability of this species to produce other forms of tetraethers including a potentially cyclised structure. However, the brGDGT Ic isomer we observe is asymmetric with two unsaturation equivalents on the same alkyl chain. BrGDGT Ic commonly found in environmental samples contains only one unsaturation (a pentacyclic ring) on each alkyl chain instead. While the unsaturation equivalents could stem from cyclisation pointing to an isomer of brGDGT Ic with a bicyclic alkyl chain, other structural variations such as double bonds and cyclohexyl rings could produce the observed mass spectrum (see Fig. 2 for two potential structures). While hydrogenation of the tetraethers did not reduce the brGDGT Ic isomer to brGDGT Ia, suggesting cyclisation instead of double bonds, tetraethers with cyclopentyl rings usually elute later under normal phase chromatography (Liu et al., 2016), not earlier as observed here. Future analyses by NMR or ether cleavage and GC-MS with a purified concentrated fraction of this trace membrane component will help determine the exact structure of this new brGDGT Ic isomer. If E. aggregans indeed produces a cyclised brGDGT it must contain a cyclisation pathway different from the archaea, as the previously described archaeal grsAB tetraether cyclisation genes (Zeng et al., 2019) do not have homologues in the E. aggregans genome. The third tetraether found in E. aggregans, brGTGT Ia, is likewise rarely identified in environmental samples but other tri-alkyl tetraethers have been previously observed. Although the exact biosynthetic pathway for branched tetraethers remains unresolved, we note the correlation between the occurrence of brGTGT Ia and elevated quantities of iso-C15.

Environmental implications. The clumping phenotype of E. aggregans highlights the potential importance of micro-scale spatial $\mathrm{O}_{2}$ gradients in brGDGT production and is supported by E. aggregans growth on solid medium; unlike in liquid cultures, we observed measurable quantities of both brGDGT Ia and the brGDGT Ic isomer in fully oxygenated $\left(21 \% \mathrm{O}_{2}\right)$ plate growth experiments (Table S-1). Aerobic plate growth and colony formation often produce micro-aerophilic environments within colonies, thus a significant portion of the plate culture likely experienced severe $\mathrm{O}_{2}$ limitation thereby triggering brGDGT production. This mode of growth on a solid substrate, rather than in liquid culture, is much more representative of the lifestyle of soil microorganisms in their natural environment (Kolter and 


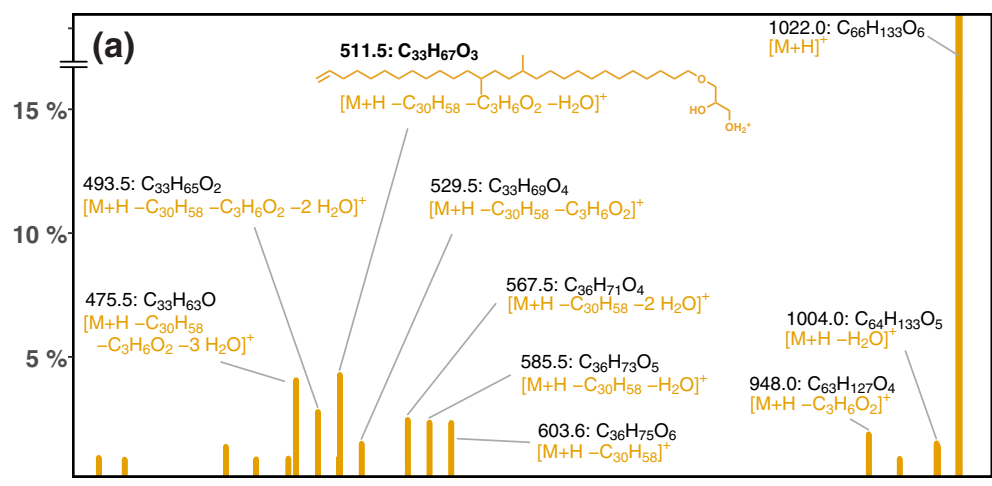

(b)
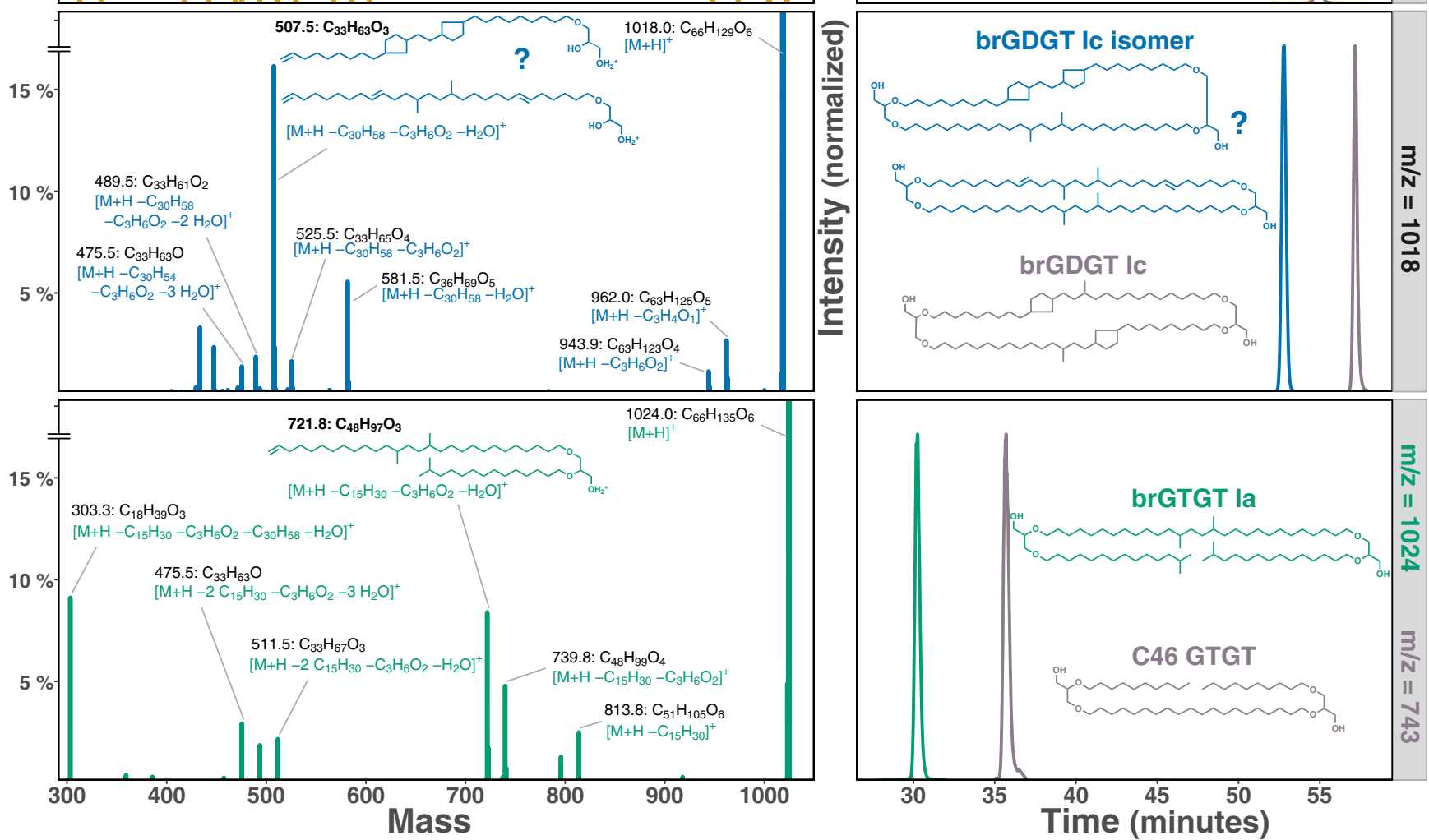

Figure 2 MS2 fragmentation and peak retention time patterns of tetraether lipids identified in $E$. aggregans using normal phase liquid chromatography. (a) MS2 fragmentation of brGTGT la (green), brGDGT Ic isomer (blue), and brGDGT la (orange). Fragment masses and formulae shown in black. Losses from the molecular ion $(\mathrm{M}+\mathrm{H}-x$.) shown in corresponding compound colour. Structures of three key identifying fragments included. (b) Peak retention times of the tetraethers identified in $E$. aggregans in comparison to structurally similar tetraethers from a soil standard and the C46 GTGT analytical standard (grey). Peak intensities are normalised.

Greenberg, 2006) and speaks to the potential importance of $\mathrm{O}_{2}$ limitation in heterogenous natural settings.

To test if all Acidobacteria exhibit similar suboxia-induced brGDGT production, we conducted follow up experiments with the well studied model organism Acidobacterium capsulatus at $1 \% \mathrm{O}_{2}$. While $A$. capsulatus also produced significant quantities of iso-diabolic acid ( $23 \pm 2 \%)$, we found no evidence of tetraether production at low $\mathrm{O}_{2}$ (Table S-1). This suggests that brGDGT production at low $\mathrm{O}_{2}$ is either not a universal trait among Acidobacteria, or that biosynthetic activation thresholds differ between organisms. Future genetic work with E. aggregans and additional culturing work with other Acidobacteria will help establish how widespread the genes for brGDGT production are in this phylum and under what conditions brGDGT biosynthesis occurs.

Palaeoclimate proxies. Although E. aggregans does not make a sufficiently large number of different tetraethers to test the mechanistic links between physiology and brGDGT-based climate proxies such as MBT and CBT, the results presented here show clearly that $\mathrm{O}_{2}$ limitation can be a trigger for brGDGT production. Because modern environmental calibrations rely on the relative distribution of brGDGTs in environmental samples, they are susceptible to abundance changes in any one structure. Although calibration data have demonstrated strong relationships between brGDGT distributions and environmental conditions like temperature and $\mathrm{pH}$, dissolved $\mathrm{O}_{2}$ measurements are limited in existing calibration data (Raberg et al., 2021). It is therefore unknown whether this variable is implicitly captured or mostly unaccounted for in modern calibrations. Recent environmental observations indicate that the abundance of other brGDGTs not detected in this study (e.g., brGDGT IIa and IIIa) may also respond to redox conditions (Weber et al., 2018; Yao et al., 2020). Holocene palaeoclimate records from the Arctic show a decoupling between known temperature trends and brGDGT-inferred temperatures (e.g., Kusch et al., 2019) suggesting an alternative overriding environmental control that is 
unaccounted for. Our results suggest that for at least one source organism dissolved oxygen is the primary gradient to which brGDGT biosynthesis responds.

\section{Conclusions}

Our results indicate that $\mathrm{O}_{2}$ availability controls biosynthesis of branched tetraethers by E. aggregans, with low $\mathrm{O}_{2}$ required for production. This is the first confirmed organism to consistently produce significant quantities of multiple brGDGTs, thus opening the door to rigorous laboratory examination to elucidate the biosynthetic pathways and biological function of these enigmatic lipids. The identification of the enzymes involved in the synthesis of brGDGTs in E. aggregans will aid in the identification of other bacterial species that produce brGDGTs and help uncover the effect that $\mathrm{O}_{2}$ limitation may have on brGDGT biosynthesis and palaeoclimate proxies.

\section{Author Contributions}

TAH, ADY and SHK designed the research. TAH, JMM, ADY, JD and ND performed the research. TAH and SHK analysed the data. TAH, JMM and SHK wrote the paper.

\section{Acknowledgments}

This research was supported by the Department of Geological Sciences at the University of Colorado Boulder and an NSF CAREER grant (EAR1945484) to SHK. We would like to thank J. Raberg and J. Sepúlveda for their analytical support and generous feedback.

Editor: Tanja Bosak

\section{Additional Information}

Supplementary Information accompanies this letter at https:// www.geochemicalperspectivesletters.org/article2132.

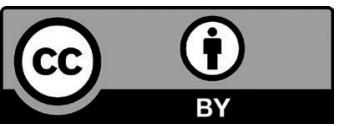

(C) 2021 The Authors. This work is distributed under the Creative Commons Attribution 4.0 License, which permits unrestricted use, distribution, and reproduction in any medium, provided the original author and source are credited. Additional information is available at http://www.geochemicalperspectivesletters.org/ copyright-and-permissions.

Cite this letter as: Halamka, T.A., McFarlin, J.M., Younkin, A.D., Depoy, J., Dildar, N., Kopf, S.H. (2021) Oxygen limitation can trigger the production of branched GDGTs in culture. Geochem. Persp. Let. 19, 36-39.

\section{References}

Boyer, G.M., Schubotz, F., Summons, R.E., Woods, J., Shock, E.L. (2020) Carbon Oxidation State in Microbial Polar Lipids Suggests Adaptation to Hot Spring Temperature and Redox Gradients. Frontiers in Microbiology 11, 229.

De Jonge, C., Hopmans, E.C., Zell, C.I., Kim, J.-H., Schouten, S., Sinninghe DAMSTÉ, J.S. (2014) Occurrence and abundance of 6-methyl branched glycerol dialkyl glycerol tetraethers in soils: Implications for palaeoclimate reconstruction. Geochimica et Cosmochimica Acta 141, 97-112.

Eichorst, S.A., Trojan, D., Roux, S., Herbold, C., Rattei, T., Woebken, D. (2018) Genomic insights into the Acidobacteriareveal strategies for their success in terrestrial environments. Environmental Microbiology 20, 1041-1063.
Kolter, R., Greenberg, E.P. (2006) The superficial life of microbes. Nature 441, 300-302.

Kusch, S., Bennike, O., Wagner, B., Lenz, M., Steffen, I., Rethemeyer, J. (2019) Holocene environmental history in high-Arctic North Greenland revealed by a combined biomarker and macrofossil approach. Boreas 48, 273-286.

Lincoln, S.A., Bradley, A.S., Newman, S.A., Summons, R.E. (2013) Organic Geochemistry Archaeal and bacterial glycerol dialkyl glycerol tetraether lipids in chimneys of the Lost City Hydrothermal Field. Organic Geochemistry 60, 45-53.

LiU, X.-L., Zhu, C., WaKeHAM, S.G., HinRichs, K.-U. (2014) In situ production of branched glycerol dialkyl glycerol tetraethers in anoxic marine water columns. Marine Chemistry 166, 1-8.

Liu, X.-L., De Santiago Torio, A., BosaK, T., Summons, R.E. (2016) Novel archaeal tetraether lipids with a cyclohexyl ring identified in Fayetteville Green Lake, NY, and other sulfidic lacustrine settings. Rapid Communications in Mass Spectrometry 30, 1197-1205.

Martínez-Sosa, P., Tierney, J.E. (2019) Lacustrine brGDGT response to microcosm and mesocosm incubations. Organic Geochemistry 127, 12-22.

NaAfs, B.D.A., Gallego-Sala, A.V., Inglis, G.N., Pancost, R.D. (2017) Refining the global branched glycerol dialkyl glycerol tetraether (brGDGT) soil temperature calibration. Organic Geochemistry 106, 48-56.

Peterse, F., van der Meer, J., Schouten, S., Weijers, J.W.H.H., Fierer, N., Jackson, R.B., KIM, J.-H.H., Sinninghe Damsté, J.S. (2012) Revised calibration of the MBT-CBT paleotemperature proxy based on branched tetraether membrane lipids in surface soils. Geochimica et Cosmochimica Acta 96, 215-229.

Pitcher, R.S., Watmough, N.J. (2004) The bacterial cytochrome cbb3 oxidases. Biochimica et Biophysica Acta 1655, 388-399.

Qin, W., Carlson, L.T., Armbrust, E.V., Devol, A.H., Moffett, J.W., Stahl, D.A., INGALLS, A.E. (2015) Confounding effects of oxygen and temperature on the TEX86 signature of marine Thaumarchaeota. Proceedings of the National Academy of Sciences 112, 10979-10984.

Raberg, J.H., Harning, D.J., Crump, S.E., de Wet, G., Blumm, A., Kopf, S., GeirsDótTIR, Á., Miller, G.H., SEPúlveda, J. (2021) Revised fractional abundances and warm-season temperatures substantially improve brGDGT calibrations in lake sediments. Biogeosciences Discussions 2021, 1-36.

Sinninghe Damsté, J.S., Rijpstra, W.I.C., Hopmans, E.C., Weijers, J.W.H., Foesel, B.U., OvermanN, J., Dedysh, S.N. (2011) 13,16-Dimethyl Octacosanedioic Acid (iso-Diabolic Acid), a Common Membrane-Spanning Lipid of Acidobacteria Subdivisions 1 and 3. Applied and Environmental Microbiology 77, 4147-4154.

Sinninghe Damsté, J.S., Rijpstra, W.I.C., Foesel, B.U., Huber, K.J., Overmann, J., Nakagawa, S., Kim, J.J., Dunfield, P.F., Dedysh, S.N., Villanueva, L. (2018) An overview of the occurrence of ether- and ester-linked isodiabolic acid membrane lipids in microbial cultures of the Acidobacteria: Implications for brGDGT paleoproxies for temperature and $\mathrm{pH}$. Organic Geochemistry 124, 63-76.

Van de VossenberG, J.L.C.M., Driessen, A.J.M., Konings, W.N. (1998) The essence of being extremophilic: The role of the unique archaeal membrane lipids. Extremophiles 2, 163-170.

WANG, M., ZHeNG, Z., ZONG, Y., MAN, M., TIAN, L. (2019) Distributions of soil branched glycerol dialkyl glycerol tetraethers from different climate regions of China. Scientific Reports 9, 1-8.

Weber, Y., Damsté, J.S.S., Zopfi, J., De Jonge, C., Gilli, A., Schubert, C.J., Lepori, F., Lehmann, M.F., Niemann, H. (2018) Redox-dependent niche differentiation provides evidence for multiple bacterial sources of glycerol tetraether lipids in lakes. Proceedings of the National Academy of Sciences 115, 10926-10931.

Weijers, J.W.H., Schouten, S., van den Donker, J.C., Hopmans, E.C., Sinninghe DAMSTÉ, J.S. (2007) Environmental controls on bacterial tetraether membrane lipid distribution in soils. Geochimica et Cosmochimica Acta 71, 703-713.

Wessel, A.K., Arshad, T.A., Fitzpatrick, M., Connell, J.L., Bonnecaze, R.T., SHEAR, J.B., Whiteley, M. (2014) Oxygen limitation within a bacterial aggregate. mBio 5, 1-9.

YaO, Y., ZhaO, J., Vachula, R.S., Werne, J.P., Wu, J., Song, X., Huna, Y. (2020) Correlation between the ratio of 5-methyl hexamethylated to pentamethylated branched GDGTs (HP5) and water depth reflects redox variations in stratified lakes. Organic Geochemistry 147, 104076.

ZenG, Z., Liu, X.L., Farley, K.R., Wei, J.H., Metcalf, W.W., Summons, R.E., WeLANDER, P.V. (2019) GDGT cyclization proteins identify the dominant archaeal sources of tetraether lipids in the ocean. Proceedings of the National Academy of Sciences 116, 22505-22511. 